Full Length Article

\title{
Do $5 \%$ changes around maximal lactate steady state lead to swimming biophysical modifications?
}

\author{
Jailton Gregório Pelarigo a,b,c,d,*, Camila Coelho Greco ${ }^{\mathrm{e}}$, Benedito Sérgio Denadai ${ }^{\mathrm{e}}$, \\ Ricardo Jorge Fernandes ${ }^{\mathrm{c}, \mathrm{d}}$, João Paulo Vilas-Boas ${ }^{\mathrm{c}, \mathrm{d}}$, David Robert Pendergast ${ }^{\mathrm{f}}$ \\ ${ }^{a}$ University Catholic Center of Quixadá - UNICATÓLICA, Quixadá, Ceará, Brazil \\ ${ }^{\mathrm{b}}$ Metropolitan College of Grande Fortaleza - FAMETRO, Fortaleza, Ceará, Brazil \\ ${ }^{\mathrm{c}}$ Centre of Research, Education, Innovation and Intervention in Sport, Faculty of Sport, University of Porto, Portugal \\ ${ }^{\mathrm{d}}$ Porto Biomechanics Laboratory, LABIOMEP, University of Porto, Portugal \\ ${ }^{\mathrm{e}}$ Human Performance Laboratory, Physical Education Department, São Paulo State University - UNESP, Rio Claro, São Paulo, Brazil \\ ${ }^{\mathrm{f}}$ Center for Research and Education in Special Environments, Department of Physiology and Biophysics, State University of New York at Buffalo, Buffalo, NY, USA
}

\section{A R T I C L E I N F O}

\section{Article history:}

Received 6 March 2016

Revised 24 July 2016

Accepted 25 July 2016

Available online 9 August 2016

\section{Keywords:}

Aerobic capacity

Gas exchange

Oxygen uptake

Oxygen uptake efficiency

Biomechanical parameters

\begin{abstract}
A B S T R A C T
Our purpose was to examine the swimming biophysical responses at velocities (v) of 97.5, 100 and $102.5 \%$ of the maximal lactate steady state (MLSS). Ten elite female swimmers performed three-to-five 30-min constant tests at imposed paces to determine 97.5, 100 and 102.5\%MLSS v. Gas exchange, blood lactate concentration ([La-]), stroke rate (SR) and $\mathrm{v}$ were determined during each test. The $\mathrm{v}$ values at 97.5, 100 and 102.5\%MLSS were $1.21 \pm 0.07,1.24 \pm 0.07$ and $1.27 \pm 0.07 \mathrm{~m} . \mathrm{s}^{-1}$, respectively. Oxygen uptake $\left(\mathrm{VO}_{2}\right)$ and Pulmonary ventilation ( $\dot{V E})$ increased as function of $v$. SR and stroke length $(v / S R=S L)$ increased as a function of $\mathrm{v}$. All measured variables were constant as a function of time at $97.5 \%$ MLSS and $100 \%$ MLSS. At $102.5 \%$ MLSS SR increased (3.5\%) and stroke length (SL) decreased (3.5\%) as a function of time. While $\mathrm{VO}_{2}$ was constant at $102.5 \% \mathrm{MLSS}$, [La-] and $\dot{V}$ E increased as a function of time, suggesting hyperventilation, at v's of 97.5\%MLSS and $100 \%$ MLSS swimmers completed the $30 \mathrm{~min}$ swim in spite of decreased SL and increased SR. However, the decrease in SL and increased SF were accompanied by increased [La-] and VE and resulted in the inability of most swimmers to complete the 30 min swim presumably due to fatigue at $102.5 \%$ MLSS.
\end{abstract}

(C) 2016 Elsevier B.V. All rights reserved.

\section{Introduction}

At low exercise intensities metabolism is from primarily aerobic sources. However, when exercise intensity increases to near or above maximal aerobic power a mixture of aerobic and anaerobic sources are used, leading to time dependent increase in muscle and blood lactate. Since the 1960s, researchers have struggled to understand and define the physiologic state where there is a significant increase in blood lactate concentration ([La-]) (anaerobic threshold - AnT). Of these attempts, a recent initial definition was termed endurance performance limit (Hollmann, 2001), which has been redefined as aerobic-anaerobic threshold, individual anaerobic threshold, anaerobic threshold, lactate turnpoint, and individual lactate minimum, among other terms (Faude, Kindermann, \& Meyer, 2009). Another concept related the AnT to the maximal

\footnotetext{
* Corresponding author at: 25 de março, 200, Ap 2403, Fortaleza, Ceará, Brazil.

E-mail address: jailtongp@hotmail.com (J.G. Pelarigo).
} 
intensity that can be maintained as function of time without blood lactate accumulation, i.e. the maximal lactate steady state - MLSS (Beneke, 2003). This exercise intensity has been used for the evaluation of aerobic capacity for endurance performance and training prescription (Beneke \& von Duvillard, 1996; Faude et al., 2009).

The MLSS is considered by many as the direct method for the evaluation of aerobic capacity (Beneke, 2003; Beneke \& von Duvillard, 1996; Faude et al., 2009). MLSS is identified as the highest steady state [La-] that can be maintained during prolonged sub-maximal and constant workload exercise (Beneke, 2003; Beneke \& von Duvillard, 1996). At intensities below and at the MLSS there is a steady-state of [La-] as function of time and exercise can be sustained (Baron, Dekerle, Depretz, Lefevre, \& Pelayo, 2005). However, when the exercise is performed at intensities above the MLSS intensity, a significant increase in [La-] is observed as function of time, which is associated with voluntary exhaustion (Beneke \& von Duvillard, 1996; Heck et al., 1985).

Although the concepts of AnT and MLSS have been previously used to characterize swimming performance, it is commonly accepted that there are bioenergetical and biomechanical factors that may influence these parameters. Further examination of these factors is needed to better understand their possible interaction, helping to understand the swimmers' adjustments that occur at intensities around MLSS (Faude et al., 2009) and as a function of swimming time.

The inability to maintain a predetermined swimming intensity (fatigue) may be due to the inability to sustain optimal biomechanical parameters, as the aerobic system bioenergetics has been shown to be stable as a function of time (Baron et al., 2005). Physiological mechanisms other than metabolism may be time-dependent, such as the ability to sustain force and its application to the water (Baron et al., 2005; Dekerle, Nesi et al., 2005; Pelarigo, Denadai, \& Greco, 2011). Thus, biomechanical factors could change the MLSS swimming velocity (v) (Pelarigo et al., 2011), leading to a reduced v or swim time.

We are unaware of any studies that have evaluated bioenergetical and biomechanical factors at intensities at or around the $100 \%$ MLSS in swimming. To examine the interrelationships of biophysical factors they must be evaluated not only as a function of intensity, but also as a function of exercise duration to understand what limits performance at these v's. Thus, the purpose of this study was to analyze the responses of bioenergetical and biomechanical factors while swimming at 97.5, 100 and 102.5\%MLSS. We hypothesized that swimming intensities up to $100 \%$ MLSS would not require progressive adjustments of bioenergetical and biomechanical factors and not limit exercise endurance up to $30 \mathrm{~min}$. However, we hypothesized that swimming above $100 \%$ MLSS would compromise bioenergetical and biomechanical factors which would affect the swimmers ability to sustain set exercise intensities (v) for $30 \mathrm{~min}$.

\section{Methods}

Ten elite female swimmers (mean \pm SD; aged $17.6 \pm 1.9$ years, height $1.70 \pm 0.05 \mathrm{~m}$, body mass $61.3 \pm 5.8 \mathrm{~kg}$ and percentage of body fat mass $15.5 \pm 2.9 \%$; maximal oxygen uptake $-\dot{\mathrm{VO}}_{2 \max } 54.9 \pm 6.7 \mathrm{~mL} . \mathrm{kg}$. $\mathrm{min}^{-1}$ ), who specialized in middle- and long-distance swimming events participated in the present study. The measurements of body mass and fat were assessed by a segmental body composition analyzer (Tanita, TBF 305, Tokyo, Japan).

Subjects had, at the least, seven years of experience as competitive swimmers and their mean performance over the $400 \mathrm{~m}$ freestyle swim was $88.0 \pm 3.4 \%$ of the 2016 short course world record. The study was approved by the local ethics committee and was performed according to the Declaration of Helsinki. Subjects and/or parents gave their written informed consent before participation in experiments.

The test sessions were performed in a $25 \mathrm{~m}$ indoor swimming pool, with water temperature of $27-28{ }^{\circ} \mathrm{C}$ and air humidity of $40-60 \%$. Swimmers were advised to refrain from intense training for at least $24 \mathrm{~h}$ before the experiments. The tests were all conducted within a seven day period, at the same time of the day $( \pm 2 \mathrm{~h})$ to minimize the effect of circadian rhythm. In all test sessions, the swimmers performed a $1000 \mathrm{~m}$ warm-up at low/moderate aerobic intensity. During the tests, swimmers swam front crawl and used in-water starts and open turns without underwater glides.

First, the swimmers performed an intermittent progressive protocol until voluntary exhaustion to determine the individual anaerobic threshold (IAnT). The predetermined initial $v$ of the swim was set at $\sim 80 \%$ of the subject's best time for the $400 \mathrm{~m}$ front crawl race (S400), the $\mathrm{v}$ was increased by $0.05 \mathrm{~m} \cdot \mathrm{s}^{-1}$ for each subsequent step until voluntary exhaustion. Thirty seconds rest intervals were observed in-between each swim. The distance of each step of the incremental test was $200 \mathrm{~m}$.

Earlobe capillary blood samples $(5 \mu \mathrm{L})$ were collected and analyzed for [La-] with a portable lactate analyzer (Lactate Pro, Arkray, Inc., Kyoto, Japan). [La-] was measured at rest and in the first $30 \mathrm{~s}$ after each step of the incremental test and, immediately after exhaustion and at each 2 min of recovery from the last step until the [La-] peak was found. The IAnT was assessed by the relationship between [La-] and $\mathrm{v}$ with the lactate inflexion point determined as the interception between a linear and exponential regressions to estimate the $\mathrm{v}$ where [La-] increased exponentially (Fernandes et al., 2006; Machado, Almeida, Morais, Fernandes, \& Vilas-Boas, 2006). If a swimmer did not achieve their maximal v and/or exhaustion with the pre-defined increases in $\mathrm{v}$, the fastest $\mathrm{v}$ the subject completed was used to determine the minimum $\mathrm{v}$ eliciting the $\dot{\mathrm{V}} \mathrm{O}_{2 \max }$.

After determining IAnT, each swimmer performed three-to-five 30 min submaximal constant swimming tests at imposed paces to assess the $\mathrm{v}$ where a MLSS was achieved and maintained (100\%MLSS). The swimming $\mathrm{v}$ was set and maintained using a visual underwater pacer (GBK-Pacer, GBK Electronics, Aveiro, Portugal), with a light strip on the bottom of the pool. The light strip had lights located $2.5 \mathrm{~m}$ apart for $25 \mathrm{~m}$. The swimmers followed the flashing lights to maintain the predetermined v's. The swimmers were instructed to swim at a speed by looking at and following the visual signal as the lights 
proceeded along the pool length. Exhaustion was defined and the test finalized when the swimmers remained $5 \mathrm{~m}$ behind the lights. A $24 \mathrm{~h}$ interval was imposed between all the tests.

[La-] was determined at rest, and at the 10th and 30th min (or voluntary exhaustion) of each continuous test as described above. The first trial was performed at the IAnT v, and, if during the first trial a steady state or a decrease in [La-] was observed, further subsequent trials with $2.5 \%$ higher v were performed until no [La-] steady state was observed. If the first trial resulted in a clearly identifiable increase of the [La-] and/or could not be sustained due to exhaustion, further trials were conducted with subsequently reduced v's (Pelarigo et al., 2011). The MLSS was defined as the highest [La-] that increased by no more than $1 \mathrm{mmol} . \mathrm{L}^{-1}$ between the 10 th and the 30th min of the test (Heck et al., 1985). The corresponding [La-] value was assumed to be the average of the value at the 10th and 30th min of exercise.

Bioenergetical factors were divided into two categories: oxygen uptake $\left(\mathrm{VO}_{2}\right)$ and total energy expenditure $(\dot{\mathrm{E}})$. The latter was the product of $\mathrm{VO}_{2}$ and caloric equivalent estimated from respiratory exchange ratio. The energy cost of swimming (C) per unit distance was calculated from $\dot{\mathrm{E}}$ and $\mathrm{v}(\dot{\mathrm{E}} / \mathrm{v}=\mathrm{C})$ and was termed economy. $\dot{\mathrm{VO}}_{2}$ was calculated from measures of expired ventilation ( $\dot{\mathrm{VE}}$ ) and $\mathrm{O}_{2}$ and $\mathrm{CO}_{2}$ fractions by a telemetric portable analyzer (K4b ${ }^{2}$, Cosmed, Italy), using standard equations. The end-tidal $\mathrm{CO}_{2}\left(\mathrm{ETP}_{\mathrm{a}} \mathrm{CO}_{2}\right)$ was used as an estimate of the arterial $\mathrm{CO}_{2}$. The analyzer was connected to the swimmer by a low hydrodynamic resistance respiratory snorkel and valve system (New AquaTrainer ${ }^{\circledR}$, Cosmed, Italy). This system has been previously validated and used in similar studies (Baldari et al., 2013; Sousa, Vilas-Boas, \& Fernandes, 2014). The equipment was calibrated prior to each swim for $\dot{V}$ E with a calibrated syringe and the $\mathrm{O}_{2}$ and $\mathrm{CO}_{2}$ analyzers with standard calibration gases. The values of gas exchange were measured breath-by-breath during all the tests and averaged every $5 \mathrm{~s}$ (Fernandes et al., 2012). The ratio of $\dot{\mathrm{VO}}_{2}$ and $\dot{\mathrm{VE}}$ was calculated and termed oxygen uptake efficiency (OUE) for all conditions (Baba et al., 1996). Heart rate (HR) was monitored and registered continuously by a HR monitor system (Polar Vantage NV, Polar electro Oy, Kempele, Finland) and transferred telemetrically to the $\mathrm{K}_{4} \mathrm{~b}^{2}$ device. The values of HR were also averaged for $5 \mathrm{~s}$ intervals.

The energetic parameters were $\dot{\mathrm{E}}$ and $\mathrm{C}$. The $\mathrm{C}$ was determined using the caloric equivalent of the $\dot{\mathrm{VO}}_{2}\left(\mathrm{kcal}^{\mathrm{L}} \mathrm{L}^{-1} \mathrm{O}_{2}\right) \mathrm{cal}^{-}$ culated by the respiratory exchange quotient (Fletcher, Esau, \& Macintosh, 2009). The C was calculated using the Eq. (1):

$$
\mathrm{C}=\dot{\mathrm{VO}} \mathrm{O}_{2} \text { caloric equivalent } \cdot \mathrm{v}^{-1}
$$

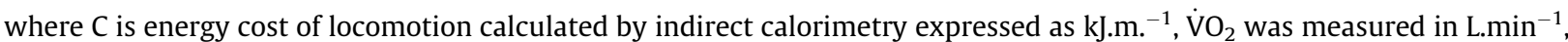
caloric equivalent is in $\mathrm{kcal} . \mathrm{L}^{-1}$, and $\mathrm{v}$ is velocity in $\mathrm{m} . \mathrm{min}^{-1}$. The energy equivalent was converted to SI units, where $1 \mathrm{kcal}$ is equivalent to $4.184 \mathrm{~kJ}$.

$$
\dot{\mathrm{E}} \cdot \mathrm{kg}^{-1}=\mathrm{C} \cdot \mathrm{V}
$$

The $\dot{\mathrm{E}}$ was determined by the product of $\mathrm{C}$ and $\mathrm{v}$, corrected by the body mass, where $\dot{\mathrm{E}}$ is the total energy expenditure expressed as $\mathrm{mL} \cdot \mathrm{kg}^{-1} \cdot \mathrm{min}^{-1}, \mathrm{C}$ as $\mathrm{kJ} \cdot \mathrm{m}^{-1}, \mathrm{v}$ is velocity in $\mathrm{m} \cdot \mathrm{min}^{-1}$, body mass is in $\mathrm{kg}$. The energy equivalents were converted into the SI units according to di Prampero (1986) where $1 \mathrm{~mL} \mathrm{O}_{2}$ is equivalent to $20.9 \mathrm{~J}$.

Biomechanical factors measured were stroke rate (SR), stroke length (SL) and the product of v and SL (stroke index - SI) at each v studied. The biomechanical analysis was conducted during the pure swimming phase of each lap in the middle of the pool (between 7.5 and $17.5 \mathrm{~m}$ ). SR was determined from images of an above-water video camera (DCR-HC42E, Sony, Japan) operating at a frequency of $50 \mathrm{~Hz}$. The SR and SL were determined from two limbs cycles for each condition and the data were averaged. The video data were then used to calculate $\mathrm{v}\left(\mathrm{m} . \mathrm{s}^{-1}\right)$ and SR (cycles.min $\left.{ }^{-1}\right)$. SR was determined by the number of upper limb cycles per unit of time and SL was calculated by the ratio of $\mathrm{v}$ and SR.

To normalize for differences in $\mathrm{v}$ and time for each subject, the data for the continuous tests at 97.5, 100 and 102.5\%MLSS v's were normalized to the total time of each swim (100\%). The data were split into eight time points corresponding to rest, the initial steady state determined during the 4 th min of the swim and then $25,33,50,66,75$ and $100 \%$ of the total duration of exercise.

The data are presented as mean and standard deviation $( \pm \mathrm{SD})$. Normality and sphericity of data were checked with the Shapiro-Wilk's W and Mauchley tests. When the assumption was not attained, Greenhouse-Geisser or the Huynh-Feld adjusted univariate tests for repeated measures were used. Beyond descriptive statistics, the analyses of $\dot{V O}_{2}$, $\mathrm{VE}_{\text {and }} \mathrm{C}$ and SR, SL and SI were performed using multivariate ANOVA. The analysis of [La-] and v values were performed using the univariate ANOVA. All analyses were repeated measures ANOVAs, complemented with the Tukey correction post hoc test. The significance level of $\mathrm{p}<0.05$ was used for all comparisons.

\section{Results}

The results of the experiments are presented for the v's at 97.5, 100 and 102.5\% MLSS intensities. For each v, data at rest, at the 4 th $\mathrm{min}$, and at $25,33,50,66,75$ and $100 \%$ of swimming time are also shown. The average v values for the three conditions were different from each other, with 97.5\%MLSS slowest and 102.5\%MLSS fastest (Fig. 1). All swimmers completed the 30 min swims at 97.5 and 100\%MLSS. However, eight out of the ten swimmers were not able to maintain the predetermined v during the $30 \mathrm{~min}$ of the $102.5 \%$ MLSS swim, reaching voluntary exhaustion on average at $19.3 \pm 4.9$ min of exercise. Regarding the statistical hypothesis decomposition, the interaction effect, i.e., significance level $(p<0.05)$ between the 


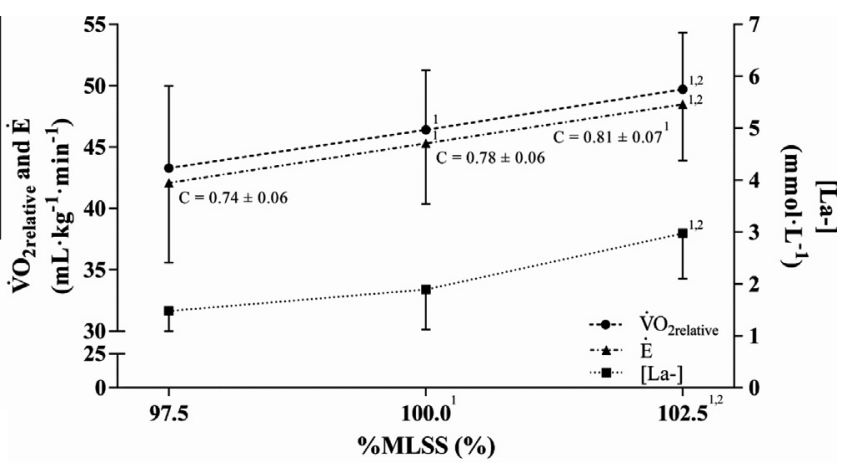

Fig. 1. Mean \pm SEMI-SD of oxygen uptake corrected for body mass ( $\left.\dot{\mathrm{VO}}_{2 \text { relative }}\right)$, total energy expenditure $(\dot{\mathrm{E}})$, energy cost of locomotion (C) and blood lactate concentration ([La-]) values at velocities corresponding to $97.5,100$ and $102.5 \%$ (slowest to highest velocity, respectively) of the maximal lactate steady state (MLSS) plotted as a function of velocity. ${ }^{1,2}$ Values significantly different to 97.5 and $100 \%$ MLSS, respectively $(p<0.05)$.

intensity and its time effects, only occurred with the $\dot{V} E$ and OUE, in which the remaining bioenergetical and biomechanical variables achieved an intensity and/or time effect.

Fig. 1 presents $\mathrm{VO}_{2}$, É, C and [La-] values as a function of v during the three swimming conditions. Oxygen uptake corrected for body mass ( $\mathrm{VO}_{2 \text { relative }}$ ) and $\dot{\mathrm{E}}$ increased significantly as a function of $\mathrm{v}$ throughout the studied intensities. $\mathrm{C}$ increased as a function of $v$ between 97.5 and $102.5 \%$ MLSS. [La-] values were similar at 97.5 and 100\%MLSS, however, the values were higher at $102.5 \%$ MLSS. Furthermore, the [La-] values as a function of time were similar at the 10th min and 30th min (or voluntary exhaustion) for $97.5\left(1.4 \pm 0.3\right.$ and $\left.1.6 \pm 0.5 \mathrm{mmol} . \mathrm{L}^{-1}\right), 100\left(1.9 \pm 0.8\right.$ and $\left.1.9 \pm 0.7 \mathrm{mmol} . \mathrm{L}^{-1}\right)$ and $102.5 \% \operatorname{MLSS}\left(2.8 \pm 0.9\right.$ and $\left.3.1 \pm 1.0 \mathrm{mmol} . \mathrm{L}^{-1}\right)$, respectively.

The bioenergetical and biomechanical parameters are presented in Table 1 . The resting values of all parameters were not different among the three swimming conditions. As expected, the $\dot{\mathrm{VO}}_{2}$, and $\dot{\mathrm{E}}$ increased significantly as a function of v. C increased as function of $\mathrm{v}$ between 97.5 and 102.5\%MLSS. $\mathrm{V}$ E increased significantly as a function of v's at $97.5,100$ and $102.5 \%$ MLSS. The HR values increased as a function of $\mathrm{v}$ and were significantly higher at $102.5 \%$ MLSS compared to $97.5 \%$ MLSS. The OUE values were lower at the 4 th min and 50, 66, 75 and 100\% of swim time at $102.5 \%$ MLSS than at $97.5 \%$ MLSS.

$\dot{\mathrm{VO}}_{2}$ did not significantly change as a function of time for v's at $97.5,100$ and $102.5 \%$ MLSS and averaged $2.62 \pm 0.04$, $2.82 \pm 0.04$ and $3.03 \pm 0.02{\mathrm{~L} . \mathrm{min}^{-1}}^{-1}$, respectively. Similarly $\dot{E}$ and C did not significantly change as a function of time for v's at $97.5,100$ and $102.5 \%$ MLSS. VE did not significantly change as a function of time for v's at 97.5 and $100 \%$ MLSS and averaged $63.94 \pm 1.29$ and $69.73 \pm 1.15 \mathrm{~L} \cdot \mathrm{min}^{-1}$, respectively. However at 102.5\%MLSS, $\dot{\mathrm{V} E}$ increased significantly as function of time from $75.7 \pm 6.7 \mathrm{~L} \cdot \mathrm{min}^{-1}$ at 4 th min to $82.9 \pm 9.4 \mathrm{~L} \cdot \mathrm{min}^{-1}$ at $100 \%$ of swim time (hyperventilation). The differences for $\mathrm{VE}$ described above have to acknowledge that there was a statistical interaction between swimming $\mathrm{v}(97.5,100$ and $102.5 \%$ MLSS) and the time points (4th min, 25, 33, 50, 66, 75 and 100\%) of measurements and for OUE.

$\mathrm{ETP}_{\mathrm{a}} \mathrm{CO}_{2}$ values were similar at all v's, at $102.5 \% \mathrm{MLSS}$, however, it showed a tendency to be lower (mean $=37.60 \mathrm{mmHg}$ ) than at the two lower v's (97.5\%MLSS - mean $=38.92 \mathrm{mmHg} ; \mathrm{p}=0.103$ and $100 \% \mathrm{MLSS}-$ mean $=38.99 \mathrm{mmHg} ; \mathrm{p}=0.083)$ and what is considered normal $\mathrm{P}_{\mathrm{a}} \mathrm{CO}_{2}(40 \mathrm{mmHg})$. Furthermore, the $\mathrm{ETP}_{\mathrm{a}} \mathrm{CO}_{2}$ values decreased as a function of time in the $102.5 \%$ MLSS swim from the start of the exercise ( 4 th $\mathrm{min})$ to its end for all swimming speeds $\left(F_{6,54}=10.328, p<0.001, \dot{\eta}_{\mathrm{p}}^{2}=0.499\right)$.

Regarding the time effect, the $\mathrm{VO}_{2}$ values were lower at the 50,66 and $100 \%$ compared to 4 th min, and at the $50 \%$ compared to $25 \%$ of exercise. Subsequent to the decreased $\mathrm{VO}_{2}, \mathrm{C}$ and $\mathrm{E}$ were lower at the $50 \%$ time compared to the 4 th min and the $25 \%$ time of exercise. The HR values increased at the all swim times compared to the 4 th min, as well as at 66,75 and $100 \%$ of exercise compared to the $25 \%$, at $75 \%$ and $100 \%$ comparing $33 \%$, and comparing $100 \%$ than at $50 \%$ time point.

OUE decreased as a function of time at the 66,75 and $100 \%$ of the $v$ at $97.5 \%$ MLSS compared to the 4 th min of exercise at $97.5 \%$ MLSS. For the $\mathrm{v}$ at $100 \%$ MLSS, OUE was significantly lower at $66 \%$ of swim time compared to the 4 th min. For the $v$ at $102.5 \%$ MLSS, OUE was significantly lower at 66,75 and $100 \%$ of swim time compared to the 4 th min and 25 and $33 \%$ of swim time exercise, and $100 \%$ of swim time compared to the $50 \%$.

Fig. 2 presents the changes in SR, SL and SI values as a function of $\mathrm{v}$ during the three swimming intensities. SR values increased as a function of $\mathrm{v}$ for all intensities. SL was lower at 102.5\%MLSS compared to 97.5 and $100 \% \mathrm{MLSS}, 4 \%$ on average across exercise times. The SI values were not significantly different among the three v's and averaged $2.61 \pm 0.02,2.68 \pm 0.03$ and $2.65 \pm 0.05 \mathrm{~m}^{2} . \mathrm{s}^{-1} \mathrm{cycle}^{-1}$, respectively.

SR's during all swims were not significantly different up to $50 \%$ of exercise time at all v's. SR's significantly increased above $50 \%$ exercise time up to $100 \%$ of exercise time at each v (3-5\%). During the $30 \mathrm{~min}$ swim, SL and SI were lower at 75\% and 100\% MLSS time compared to the 4 th min of exercise, and at $100 \%$ compared to the $33 \%$ and $50 \%$ MLSS of exercise time.

\section{Discussion}

This study analyzed the effects of intensity and time-dependent variation of bioenergetical and biomechanical factors in swimming at intensities below, at, and above the MLSS. The MLSS is considered a commonly accepted method for the 
Table 1

Bioenergetical and biomechanical parameters associated with the velocity at $97.5,100$ and $102.5 \%$ of the maximal lactate steady state (MLSS) for the 8 normalized time moments of the swims. Statistical analyses were described by intensity and/or time effect or interaction effect $(\mathrm{N}=10)$.

\begin{tabular}{|c|c|c|c|c|c|c|c|c|c|}
\hline \multirow[t]{2}{*}{ Parameters/Effect } & \multirow[t]{2}{*}{ Intensity } & \multicolumn{8}{|c|}{ Time Moments } \\
\hline & & Rest & 4th min & $25 \%$ & $33 \%$ & $50 \%$ & $66 \%$ & $75 \%$ & $100 \%$ \\
\hline $\mathrm{VO}_{2} \#^{*}\left(\mathrm{~L} \cdot \mathrm{min}^{-1}\right)$ & $\begin{array}{l}97.5 \% \text { MLSS } \\
100 \% \text { MLSS } \\
102.5 \% \text { MLSS }\end{array}$ & $\begin{array}{l}0.44(0.15) \\
0.36(0.05) \\
0.39(0.06)\end{array}$ & $\begin{array}{l}2.68(0.28) \\
2.88(0.23)^{1} \\
3.05(0.21)^{1,2}\end{array}$ & $\begin{array}{l}2.63(0.29) \\
2.88(0.22)^{1} \\
3.05(0.19)^{1,2}\end{array}$ & $\begin{array}{l}2.61(0.28) \\
2.81(0.21)^{1} \\
3.06(0.22)^{1,2}\end{array}$ & $\begin{array}{l}2.58(0.28)^{\mathrm{a}, \mathrm{b}} \\
2.78(0.19)^{1, \mathrm{a}, \mathrm{b}} \\
3.02(0.21)^{1,2, \mathrm{a}, \mathrm{b}}\end{array}$ & $\begin{array}{l}2.59(0.30)^{\mathrm{a}} \\
2.80(0.22)^{1, \mathrm{a}} \\
3.00(0.22)^{1,2, \mathrm{a}}\end{array}$ & $\begin{array}{l}2.65(0.28) \\
2.81(0.17)^{1} \\
3.03(0.21)^{1,2}\end{array}$ & $\begin{array}{l}2.63(0.28)^{\mathrm{a}} \\
2.80(0.21)^{1, \mathrm{a}} \\
3.01(0.20)^{1,2, \mathrm{a}}\end{array}$ \\
\hline$\dot{\mathrm{VE}^{\dagger}}\left(\mathrm{L} \cdot \mathrm{min}^{-1}\right)$ & $\begin{array}{l}\text { 97.5\%MLSS } \\
100 \% \text { MLSS } \\
102.5 \% \text { MLSS }\end{array}$ & $\begin{array}{l}14.7(5.0) \\
12.1(1.8) \\
14.6(4.5)\end{array}$ & $\begin{array}{l}62.4(8.1) \\
68.6(8.2)^{1} \\
75.7(6.7)^{1,2}\end{array}$ & $\begin{array}{l}63.6(9.6) \\
70.7(8.2)^{1} \\
76.3(5.8)^{1,2}\end{array}$ & $\begin{array}{l}63.3(8.7) \\
69.1(8.4)^{1} \\
76.5(7.2)^{1,2}\end{array}$ & $\begin{array}{l}62.9(8.9) \\
68.4(7.1)^{1} \\
78.4(9.6)^{1,2}\end{array}$ & $\begin{array}{l}64.7(9.5) \\
71.5(7.6)^{1} \\
79.8(8.6)^{1,2}\end{array}$ & $\begin{array}{l}66.2(10.0) \\
69.5(8.3) \\
80.5(9.3)^{1,2}\end{array}$ & $\begin{array}{l}64.5(9.3) \\
70.3(10.5)^{1} \\
82.9(9.4)^{1,2, a, b, c}\end{array}$ \\
\hline $\operatorname{OUE}^{\dagger}\left(\mathrm{mL} \mathrm{O}_{2} \cdot \mathrm{L}^{-1} \dot{\mathrm{VE}}\right)$ & $\begin{array}{l}\text { 97.5\%MLSS } \\
100 \% \text { MLSS } \\
102.5 \% \text { MLSS }\end{array}$ & $\begin{array}{l}31.0(5.7) \\
30.0(2.9) \\
28.3(5.8)\end{array}$ & $\begin{array}{l}43.3(3.5) \\
42.3(3.2) \\
40.5(3.3)^{1}\end{array}$ & $\begin{array}{l}41.8(4.2) \\
41.0(3.5) \\
40.2(3.2)\end{array}$ & $\begin{array}{l}41.5(3.8) \\
41.1(3.7) \\
40.2(3.0)\end{array}$ & $\begin{array}{l}41.3(3.5) \\
40.9(4.3) \\
38.8(4.1)^{1}\end{array}$ & $\begin{array}{l}40.4(3.2)^{\mathrm{a}} \\
39.6(4.7)^{\mathrm{a}} \\
37.9(3.9)^{1, \mathrm{a}, \mathrm{b}, \mathrm{c}}\end{array}$ & $\begin{array}{l}40.4(4.1)^{\mathrm{a}} \\
40.9(4.3) \\
38.0(4.0)^{1,2, \mathrm{a}, \mathrm{b}, \mathrm{c}}\end{array}$ & $\begin{array}{l}41.1(4.2)^{\mathrm{a}} \\
40.4(4.8) \\
36.6(4.2)^{1,2, a, b, b, c, d}\end{array}$ \\
\hline $\mathrm{HR}^{\#^{*}}(\mathrm{bpm})$ & $\begin{array}{l}\text { 97.5\%MLSS } \\
100 \% \text { MLSS } \\
102.5 \% \text { MLSS }\end{array}$ & $\begin{array}{l}77.8(11.7) \\
73.0(11.5) \\
74.1(11.6)\end{array}$ & $\begin{array}{l}160.4(16.3) \\
168.9(7.7) \\
173.0(8.8)^{1}\end{array}$ & $\begin{array}{l}165.2(15.9)^{\mathrm{a}} \\
173.3(9.8)^{\mathrm{a}} \\
176.8(10.0)^{1, a}\end{array}$ & $\begin{array}{l}166.6(14.9)^{\mathrm{a}} \\
173.8(11.2)^{\mathrm{a}} \\
178.8(10.2)^{1 \mathrm{va}}\end{array}$ & $\begin{array}{l}168.4(15.4)^{\mathrm{a}} \\
173.0(9.6)^{\mathrm{a}} \\
180.3(9.7)^{1, \mathrm{a}}\end{array}$ & $\begin{array}{l}168.4(16.2)^{\mathrm{a}, \mathrm{b}} \\
174.7(10.2)^{\mathrm{a}, \mathrm{b}} \\
181.7(9.3)^{1, \mathrm{a}, \mathrm{b}}\end{array}$ & $\begin{array}{l}170.4(14.7)^{\mathrm{a}, \mathrm{b}, \mathrm{c}} \\
175.0(10.9)^{\mathrm{a}, \mathrm{b}, \mathrm{c}} \\
182.1(9.2)^{1, \mathrm{a}, \mathrm{b}, \mathrm{c}}\end{array}$ & $\begin{array}{l}170.6(14.7)^{\mathrm{a}, \mathrm{b}, \mathrm{c}, \mathrm{d}} \\
176.3(10.5)^{\mathrm{a}, \mathrm{b}, \mathrm{c}, \mathrm{d}} \\
182.2(11.1)^{1, \mathrm{a}, \mathrm{b}, \mathrm{b}, \mathrm{d}}\end{array}$ \\
\hline $\mathrm{C}^{\# *}\left(\mathrm{~kJ} \cdot \mathrm{m}^{-1}\right)$ & $\begin{array}{l}\text { 97.5\%MLSS } \\
100 \% \text { MLSS } \\
102.5 \% \text { MLSS }^{1}\end{array}$ & $\begin{array}{l}0.17(0.04) \\
0.16(0.04) \\
0.14(0.03)\end{array}$ & $\begin{array}{l}0.75(0.06) \\
0.79(0.06) \\
0.82(0.06)^{1}\end{array}$ & $\begin{array}{l}0.74(0.07) \\
0.79(0.06) \\
0.82(0.07)^{1}\end{array}$ & $\begin{array}{l}0.73(0.06) \\
0.77(0.06) \\
0.82(0.07)^{1}\end{array}$ & $\begin{array}{l}0.72(0.05)^{\mathrm{a}, \mathrm{b}} \\
0.76(0.06)^{\mathrm{a}, \mathrm{b}} \\
0.81(0.06)^{1, \mathrm{a}, \mathrm{b}}\end{array}$ & $\begin{array}{l}0.73(0.06) \\
0.77(0.07) \\
0.81(0.07)^{1}\end{array}$ & $\begin{array}{l}0.74(0.06) \\
0.77(0.06) \\
0.81(0.07)^{1}\end{array}$ & $\begin{array}{l}0.73(0.06) \\
0.77(0.07) \\
0.81(0.07)^{1}\end{array}$ \\
\hline$\dot{\mathrm{E}}^{\# *}\left(\mathrm{~mL} \cdot \mathrm{kg}^{-1} \cdot \mathrm{min}^{-1}\right)$ & $\begin{array}{l}\text { 97.5\%MLSS } \\
100 \% \text { MLSS } \\
102.5 \% \text { MLSS }\end{array}$ & $\begin{array}{l}9.4(2.2) \\
9.2(2.8) \\
8.3(1.7)\end{array}$ & $\begin{array}{l}42.8(6.9) \\
46.0(5.4)^{1} \\
48.7(5.0)^{1,2}\end{array}$ & $\begin{array}{l}42.3(7.0) \\
46.3(5.6)^{1} \\
48.9(4.6)^{1,2}\end{array}$ & $\begin{array}{l}41.9(7.0) \\
45.3(5.9)^{1} \\
49.1(5.5)^{1,2}\end{array}$ & $\begin{array}{l}41.4(6.9)^{\mathrm{a}, \mathrm{b}} \\
44.5(5.0)^{1, \mathrm{a}, \mathrm{b}} \\
48.2(4.9)^{1,2, \mathrm{a}, \mathrm{b}}\end{array}$ & $\begin{array}{l}41.7(6.9) \\
45.2(5.2)^{1} \\
48.0(4.3)^{1,2}\end{array}$ & $\begin{array}{l}42.5(6.5) \\
45.0(4.0)^{1} \\
48.4(4.5)^{1,2}\end{array}$ & $\begin{array}{l}42.0(6.3) \\
44.8(4.8)^{1} \\
48.1(4.5)^{1,2}\end{array}$ \\
\hline $\mathrm{SR}^{\#^{*}}\left(\right.$ cycles $\left.\cdot \mathrm{min}^{-1}\right)$ & $\begin{array}{l}97.5 \% \text { MLSS } \\
100 \% \text { MLSS } \\
102.5 \% \text { MLSS }\end{array}$ & $\begin{array}{l}- \\
- \\
-\end{array}$ & $\begin{array}{l}33.4(3.3) \\
34.0(3.3) \\
35.4(3.3)\end{array}$ & $\begin{array}{l}33.8(3.4) \\
34.5(3.0)^{1} \\
36.1(3.3)^{1,2}\end{array}$ & $\begin{array}{l}33.4(3.3) \\
34.5(3.1)^{1} \\
36.2(3.1)^{1,2}\end{array}$ & $\begin{array}{l}33.6(3.4) \\
34.4(3.2)^{1} \\
36.0(3.3)^{1,2}\end{array}$ & $\begin{array}{l}33.7(3.2)^{\mathrm{a}} \\
34.8(3.6)^{1, \mathrm{a}} \\
36.7(2.8)^{1,2, \mathrm{a}}\end{array}$ & $\begin{array}{l}34.1(3.6)^{\mathrm{a}} \\
34.6(3.8)^{1, \mathrm{a}} \\
37.3(3.3)^{1,2, \mathrm{a}}\end{array}$ & $\begin{array}{l}34.2(3.5)^{\mathrm{a}, \mathrm{c}, \mathrm{d}, \mathrm{d}} \\
35.2(3.8)^{1, \mathrm{a}, \mathrm{c}, \mathrm{d}} \\
37.2(3.3)^{1,2, \mathrm{a}, \mathrm{c}, \mathrm{d}}\end{array}$ \\
\hline $\mathrm{SL}^{\# *}\left(\mathrm{~m} \cdot \mathrm{cycle}^{-1}\right)$ & $\begin{array}{l}\text { 97.5\%MLSS } \\
100 \% \text { MLSS } \\
102.5 \% \text { MLSS }\end{array}$ & $\begin{array}{l}- \\
- \\
-\end{array}$ & $\begin{array}{l}2.18(0.14) \\
2.20(0.13) \\
2.16(0.12)\end{array}$ & $\begin{array}{l}2.16(0.14) \\
2.16(0.12) \\
2.12(0.14)^{1,2}\end{array}$ & $\begin{array}{l}2.18(0.15) \\
2.17(0.14) \\
2.11(0.14)^{1,2}\end{array}$ & $\begin{array}{l}2.17(0.14) \\
2.17(0.13) \\
2.12(0.14)^{1,2}\end{array}$ & $\begin{array}{l}2.16(0.13) \\
2.15(0.15) \\
2.08(0.14)^{1,2}\end{array}$ & $\begin{array}{l}2.14(0.15)^{\mathrm{a}} \\
2.16(0.16)^{\mathrm{a}} \\
2.05(0.13)^{1,2, a}\end{array}$ & $\begin{array}{l}2.13(0.15)^{\mathrm{a}, \mathrm{c}, \mathrm{d}} \\
2.13(0.16)^{\mathrm{a}, \mathrm{c}, \mathrm{d}} \\
2.06(0.14)^{1,2, \mathrm{a}, \mathrm{a}, \mathrm{d}, \mathrm{d}}\end{array}$ \\
\hline $\mathrm{SI}^{*}\left(\mathrm{~m}^{2} \cdot \mathrm{s}^{-1} \cdot \mathrm{cycle}^{-1}\right)$ & $\begin{array}{l}\text { 97.5\%MLSS } \\
100 \% \text { MLSS } \\
102.5 \% \text { MLSS }\end{array}$ & $\begin{array}{l}- \\
- \\
-\end{array}$ & $\begin{array}{l}2.63(0.20) \\
2.72(0.19) \\
2.73(0.18)\end{array}$ & $\begin{array}{l}2.60(0.20) \\
2.68(0.21) \\
2.68(0.22)\end{array}$ & $\begin{array}{l}2.63(0.23) \\
2.69(0.22) \\
2.67(0.24)\end{array}$ & $\begin{array}{l}2.62(0.18) \\
2.69(0.19) \\
2.68(0.22)\end{array}$ & $\begin{array}{l}2.61(0.19) \\
2.66(0.21) \\
2.63(0.25)\end{array}$ & $\begin{array}{l}2.58(0.21)^{\mathrm{a}} \\
2.67(0.21)^{\mathrm{a}} \\
2.59(0.21)^{\mathrm{a}}\end{array}$ & $\begin{array}{l}2.57(0.20)^{\mathrm{a}, \mathrm{c}, \mathrm{d}} \\
2.63(0.21)^{\mathrm{a}, \mathrm{c}, \mathrm{d}} \\
2.60(0.22)^{\mathrm{a}, \mathrm{c}, \mathrm{d}}\end{array}$ \\
\hline
\end{tabular}

Intensity and/or time effect or interaction effect are indicated in each parameter.

1,2 Values significantly different to 97.5 and $100 \%$ MLSS, respectively; ${ }^{\text {a,b,c,d }}$ Values significantly different to the 4 th $\min , 25,33$ and $50 \%$, respectively ( $p<0.05$ ).

\# Intensity effect.

* Time effect.

$\dagger$ Interaction effect. 


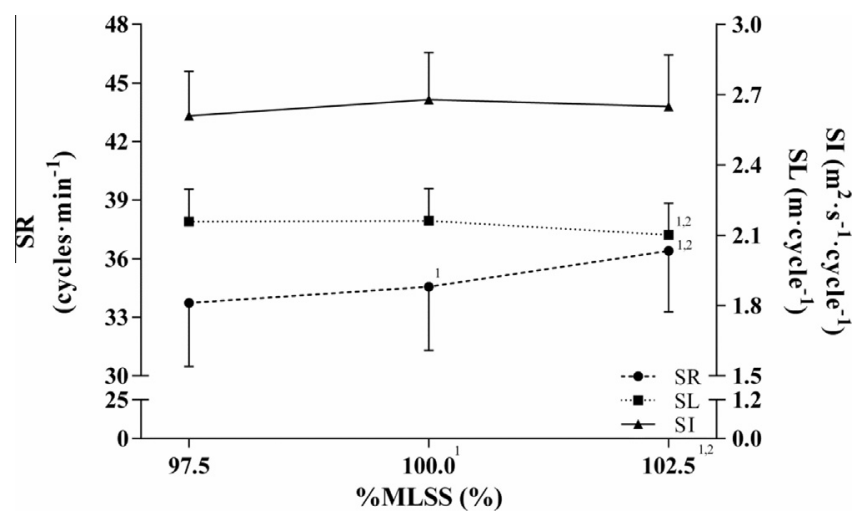

Fig. 2. Mean \pm SEMI-SD of stroke rate (SR), stroke length (SL) and stroke index (SI) values at velocities corresponding to $97.5,100$ and $102.5 \%$ (slowest to highest velocity, respectively) of the maximal lactate steady state (MLSS) plotted as a function of velocity. ${ }^{1,2}$ Values significantly different to 97.5 and $100 \%$ MLSS, respectively $(p<0.05)$.

evaluation of aerobic capacity in sports, including swimming (Beneke, 2003; Beneke \& von Duvillard, 1996; Faude et al., 2009). The main findings of the present study were: (a) $\mathrm{VO}_{2}, \mathrm{C}$ and $\dot{\mathrm{E}}$ were constant throughout the test time duration at each one of the three studied swimming intensities (97.5, 100 and 102.5\%MLSS), while HR increased as a function of time for all the three v's studied; (b) at 97.5 and 100\%MLSS, bioenergetical factors did not change as a function of time. However, SR increased and SL decreased as a function of time in the $30 \mathrm{~min}$ swims (biomechanical factors) and; (c) at 102.5\%MLSS, although the $\dot{\mathrm{VO}}_{2}$ and $\mathrm{C}$ were constant as a function of time, $\dot{\mathrm{VE}}$ and $\mathrm{HR}$ increased as a function of time. With a constant $\dot{\mathrm{VO}}_{2}$ and an increasing $\dot{\mathrm{V}}$, OUE decreased. The increased [La-] and $\dot{\mathrm{VE}}$ are also likely responsible for eight out of ten of the subjects' not completing the $30 \mathrm{~min}$ swim at $102.5 \%$ MLSS due to locomotor and respiratory muscle fatigue (Harms, Wetter, St Croix, Pegelow, \& Dempsey, 2000).

In the present study, gas exchange values $\left(\dot{\mathrm{VO}}_{2}\right.$ and $\left.\dot{\mathrm{VE}}\right)$ were directly measured breath-by-breath as a function of time for intensities below, at, and above MLSS in swimming. However, previous researchers used measurements during the recovery period which were back extrapolated to assess $\dot{\mathrm{VO}}_{2}$ and $\dot{\mathrm{VE}}$ values during prolonged continuous swimming (Baron et al., 2005; Dekerle, Nesi et al., 2005). The $\dot{\mathrm{VO}}_{2}$ values for $100 \%$ MLSS in women were lower in the present study (2.83 L.min ${ }^{-1}$ ) compared to those previously reported for men during submaximal exercise that used the back extrapolation from recovery method (4.94 L.min ${ }^{-1}$ ) (Dekerle, Nesi et al., 2005). The lower $\dot{\mathrm{VO}}_{2}$ values in the present study could be explained by differences in the sex of the subjects studied. Women have been reported to have lower muscle mass, and differences in pulmonary structure (Hopkins \& Harms, 2004; Sheel, Richards, Foster, \& Guenette, 2004). This is supported by the wellestablished lower $\mathrm{VO}_{2}$ values for female athletes compared to their male counterparts (Rodriguez \& Mader, 2011). In spite of the gender and method differences, the MLSS in the present study for women occurred at $85 \%(4 \% \mathrm{SD})$ of $\mathrm{VO}_{2 \max }$, which is similar to that reported in a previous study for men $\left(86 \% \dot{\mathrm{VO}}_{2 \text { peak }}\right)$ (Dekerle, Nesi et al., 2005), the latter based on the measurements of recovery period.

The increase in VE values as function of time during the $30 \mathrm{~min}$ swim were stable at the lower v's. However, at the highest $\mathrm{v}$ studied (102.5\%MLSS) $\dot{V}$ increased as a function of time. The increased $\dot{V} E$ in this study is in accordance with a previous study (Baron et al., 2003), who reported similar values $\left(\sim 71.6{\mathrm{~L} . \mathrm{min}^{-1}}^{-}\right)$for cycling at $100 \%$ MLSS. The time-dependent increase in $\dot{\mathrm{VE}}$, with a constant $\dot{\mathrm{VO}}_{2}$ and increased [La-] (hyperventilation), likely occurs as a respiratory compensation secondary to metabolic acidosis as seen in the present study, and likely due to the $\dot{E}$ of swimming at that velocity exceeding the aerobic supply capacity. The physiological system adjusts cardiopulmonary variables to match the oxygen delivery to the exercise intensity/v, i.e. the ratio between $\dot{\mathrm{VO}}_{2}$ and $\dot{\mathrm{V}}$. The ratio of $\dot{\mathrm{VO}}_{2} / \dot{\mathrm{VE}}$ has been described as an index of ventilatory efficiency (OUE) (Baba et al., 1996), which has also been reported to vary among different athletes (Pelarigo et al., 2014), and was decreased in this study at the highest $\mathrm{v}$, and as a function of time.

The observation that $\dot{\mathrm{VO}}_{2}$ was unchanged while $\dot{\mathrm{V}}$ increased as a function of time demonstrates that the subjects were hyperventilation. The OUE in this study decreased as a function of time at all exercise intensities. At the lowest studied $v$, the mild decrease in OUE may be explained by a slight reduction in $\mathrm{VO}_{2}$ from the 4th min throughout the swim. The reduction in $\dot{\mathrm{VO}}_{2}$ as a function of time may be explained by biomechanical adjustments to promote gross efficiency, with swimmers improving propelling efficiency and/or decreasing drag (Pelarigo et al., 2011; Toussaint \& Hollander, 1994). At the fastest $\mathrm{v}(102.5 \% \mathrm{MLSS})$, OUE showed a greater, and significant decay as a function of time compared to the lower v's. The decrease of OUE as a function of time during the swim at 102.5MLSS is likely explained by the respiratory compensation for metabolic acidosis (increased [La-]), increasing $\dot{\mathrm{VE}}$ when $\dot{\mathrm{VO}}_{2}$ remained constant (Baba et al., 1996). Alternatively, there may be an increased pulmonary dead space due to the reduction in tidal volume, and resultant increase in breathing frequency to meet the increased $\dot{V} E$ needs as previously suggested (Baba et al., 1996). If the pulmonary dead space significantly increased during exercise, the $\dot{V} E$ would have to be increased to provide the same alveolar ventilation at a higher energy cost to the respiratory muscles (Harms et al., 2000). It is possible that the increased VE (hyperventilation) observed in this study was 
respiratory compensation for metabolic acidosis due to the buildup of [La-] and also resulted in an increased pulmonary dead space. The increased [La-] and $\dot{V E}$ are also likely responsible for eight out of ten of the subjects' not completing the 30 min swim at $102.5 \%$ MLSS due to locomotor and respiratory muscle fatigue (Harms et al., 2000).

Supporting the role of respiratory compensation for metabolic acidosis at $102.5 \% \mathrm{MLSS}$ is the reduced end-tidal $\mathrm{P}_{\mathrm{a}} \mathrm{CO}_{2}$ $\left(\mathrm{ETP}_{\mathrm{a}} \mathrm{CO}_{2}\right)$ observed suggesting a decrease in arterial $\mathrm{CO}_{2}\left(\mathrm{P}_{\mathrm{a}} \mathrm{CO}_{2}\right)$. The lower $\mathrm{P}_{\mathrm{a}} \mathrm{CO}_{2}$ is involved in the buffering system and control of metabolic acidosis. $\mathrm{ETP}_{\mathrm{a}} \mathrm{CO}_{2}$ values at $102.5 \% \mathrm{MLSS}$ was lower than at the two lower v's (97.5 and $100 \% \mathrm{MLSS}$ ) and than what is considered normal $\mathrm{P}_{\mathrm{a}} \mathrm{CO}_{2}(40 \mathrm{mmHg})$. Furthermore, the $\mathrm{ETP}_{\mathrm{a}} \mathrm{CO}_{2}$ values decreased as a function of time in the 102.5\%MLSS swim from the start of the exercise (4th $\mathrm{min}$ ) to its end for all swimming speeds. Thus, the reductions in $\mathrm{ETP}_{\mathrm{a}} \mathrm{CO}_{2}$ as a function of time at all v's, and particularly for the $102.5 \% \mathrm{MLSS} \mathrm{v}$ confirm the respiratory compensation, and thus support its role in the reduced OUE.

Lower values of [La-] at 100\%MLSS (1.89 mmol.. $\left.\mathrm{L}^{-1}\right)$ were observed in the females in the present study compared to swimming literature reported data for males (2.8-3.3 mmol.. ${ }^{-1}$ ) (Dekerle, Nesi et al., 2005; Fernandes, Sousa, Machado, \& VilasBoas, 2011; Pelarigo et al., 2011). Part of this difference in the [La-] values is due to the lower [La-] values commonly observed for women compared to men in middle-distance and endurance exercise (Crewther, Cronin, \& Keogh, 2006; Greco, Pelarigo, Figueira, \& Denadai, 2007; Holfelder, Brown, \& Bubeck, 2013). The lower [La-]'s in women are likely explained by their lower body mass and lean muscle mass (Crewther et al., 2006; Holfelder et al., 2013). A further potential difference between men and women is the higher testosterone concentration in men (Deschenes \& Kraemer, 2002), which could suggest a different metabolic balance between carbohydrates and fat throughout prolonged exercises (Greco et al., 2007; Tarnopolsky, Atkinson, Phillips, \& MacDougall, 1995). Another potential factor for the low values of [La-] for women found in the present study may be due to their potentially greater adaptation of aerobic metabolism during exertion caused by their higher level of training than the men previously reported. Endurance athletes have been shown to have higher phenotypic expression of oxidative muscle fibers compared to sprint athletes (Tanaka \& Swensen, 1998). This adaptation could lead to fibers that consume lactate (Gladden, 2008), supporting a physiological steady state at intensities near the vV $\mathrm{V}_{2 \mathrm{max}}$. These adaptations may explain the low final [La-] values observed in this study as the subjects were middle-distance and endurance swimmers.

The $C$ (the ratio of $\dot{E}$ and $v$ ) has been suggested to be a major determinant of swimming performance (di Prampero, Pendergast, \& Zamparo, 2011). É has to include both aerobic and anaerobic energy sources, especially at speeds near or greater than those than can be sustained using aerobic metabolism only (Fernandes et al., 2006). In the present study C was measured by direct methods during submaximal constant swimming for MLSS assessment and the anaerobic component from an energetic equivalent from blood [La-] (di Prampero et al., 2011). C increased around $5 \%$ as a function of $\mathrm{v}$ during the three swimming v's, as a linear function of $\mathrm{v}$. Previous studies, however, reported that $\mathrm{C}$ increases with the $\mathrm{v}$ as a nonlinear function (di Prampero et al., 2011) or a cubic function (Rodriguez \& Mader, 2011). This apparent discrepancy is likely explained by differences in the ranges of v's studied, more narrow in the present study and wider in the studies showing a nonlinear relationship for v. Previous studies used very low to maximal swimming v's (Rodriguez \& Mader, 2011), contrasted

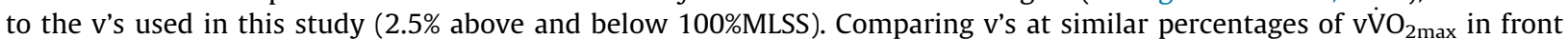
crawl swimming used in this study, $C$ values of $37.9 \mathrm{~mL} \cdot \mathrm{m}^{-1}\left(0.79 \mathrm{~kJ} \cdot \mathrm{m}^{-1}\right)$ and $41 \mathrm{~mL} \cdot \mathrm{m}^{-1}\left(0.86 \mathrm{~kJ} \cdot \mathrm{m}^{-1}\right)$ for high level female swimmers at mean intensity values of $88 \%$ and $95 \%$ of maximum $400 \mathrm{~m}$ speed, respectively, have previously been reported (Chatard, Lavoie, \& Lacour, 1991). The $400 \mathrm{~m}$ race in swimming has been highly associated with the minimum $\mathrm{v}$ that elicits $\dot{\mathrm{VO}}_{2 \max }$ (Costill et al., 1985). Although the methodological approach (maximal $400 \mathrm{~m} v s$ progressive protocol) and the exercise mode (continuous vs intermittent) used in these studies were different (Chatard et al., 1991), the mean values of $C$ were similar to those of the present study $\left(0.78\right.$ and $0.81 \mathrm{~kJ} \cdot \mathrm{m}^{-1}$ at 100 and $102.5 \mathrm{MLSS}$, respectively).

HR presented similar adjustments as a function of time among the three swimming conditions in the present study, drifting up around $10 \mathrm{bpm}$ from the 4th min to the end of the test. The increased HR observed in prolonged exercise, as in the present study, defined as “cardiovascular drift” (Fritzsche, Switzer, Hodgkinson, \& Coyle, 1999), is likely explained by an increase in sympathetic nervous system activity and circulating norepinephrine concentrations, as well as other mechanisms to maintain cardiac output (Baron et al., 2008). The mean HR value at $100 \%$ MLSS was of $92 \%\left(\mathrm{SD} 4 \%\right.$ ) of $\mathrm{HR}^{2}$ at $\mathrm{VO}_{2 \mathrm{max}}$ in the present study, a value which is similar to that previously reported (Dekerle, Nesi et al., 2005; Dekerle, Pelayo et al., 2005).

The v values at 100\%MLSS for females reported in this study are similar to those reported for males in previous studies (Baron et al., 2005; Dekerle, Pelayo et al., 2005; Pelarigo et al., 2011). In addition the SR, SL and SI values reported in those same studies using men (Baron et al., 2005; Dekerle, Pelayo et al., 2005; Pelarigo et al., 2011) are similar to those reported in this study for women. These similarities of the male data from previous studies and the current study are most likely due to the high technical and training level of our swimmers. This assertion is strengthened by the $\mathrm{v}$ at $100 \% \mathrm{MLSS}$ expressed as a percentage of $\mathrm{vVO}_{2 \max }$ observed in the present study $(91.8 \pm 4.6 \%)$ compared to previous reports in swimming (88.9 $\pm 3.3 \%$ ) (Dekerle, Nesi et al., 2005), cycling (78.2 \pm 4.9\%), and running (75.9 \pm 5.1\%) (Figueira, Caputo, Pelarigo, \& Denadai, 2008).

Swimming v is obtained by the product of SR and SL (Craig \& Pendergast, 1979). It has also been shown that fatigue may interfere with the stroking parameters adopted by the swimmers to maintain a given v (Pelarigo et al., 2011). In the present study, swimmers did not sustain their SL at 102.5\%MLSS compared to 97.5 and 100\%MLSS, and thus they had to increased their SR to maintain their paced v. Indeed, the decline in SL as a function of v resulted in a decrease in SI, suggesting the importance of the ability to maintain biomechanical efficiency with exercise intensity. These findings are in agreement with previous studies, who reported decreases in SL and increases in SR in all-out distance trials (Craig \& Pendergast, 1979) and with time at imposed paces (Dekerle, Nesi et al., 2005; Figueiredo et al., 2014; Pelarigo et al., 2011). In addition, SR values in 
this study increased in the final periods of the 30 min swims compared to the beginning of the swims (4th min). Conversely, SL and SI were lower in the final periods of the swims compared with the beginning of the swims (4th min). A previous study (Dekerle, Nesi et al., 2005) reported that, at 100\%MLSS, there was a slight decrease of SL (-3.3\%) and increase of SR (3.6\%) (non-significant in absolute values), from the beginning to the end of exercise, respectively. Similar trends in SL and SR were found in the present study during 100\%MLSS exercise. Moreover, at 102.5\%MLSS fatigue likely developed as a function of time and was associated with the SL decrease ( $-4 \%)$, and the SR increase (4.3\%) from the beginning to the end of exercise. The biomechanical data show that for all three swimming v's, SR had to be increased to compensate for the reduced SL to keep v constant as set by the protocol. In spite of these stroke mechanics changes $\dot{\mathrm{E}}$ and $\mathrm{C}$ were not affected. As $\dot{\mathrm{E}}$ and $\mathrm{C}$ are determined by drag and net mechanical efficiency the absences of changes in $\dot{E}$ suggest either or both drag and net mechanical efficiency did not change.

\section{Conclusions}

Our results suggest that, at intensities up to the MLSS, bioenergetical and biomechanical factors are constant as a function of time in a 30 min swim. However, above the MLSS (102.5\%MLSS) there was a decrease in $\mathrm{ETP}_{\mathrm{a}} \mathrm{CO}_{2} \mathrm{Which}$ is a result of hyperventilation $\left(\dot{\mathrm{V} E} / \dot{\mathrm{VO}}_{2}\right.$ ), most likely caused by respiratory compensation for metabolic acidosis (increased [La-]), thus decreasing OUE. As $\mathrm{VO}_{2}$ was constant over the $30 \mathrm{~min}$ swim at all v's, increased [La-] and SR most likely caused fatigue and, together, were associated with the inability of most swimmers to complete the 30 min swim at $102.5 \% \mathrm{MLSS}$.

\section{Acknowledgements}

This investigation was supported by the Capes Foundation, Ministry of Education of Brazil under Grant (BEX: 0536/10-5), and the Portuguese Science and Technology Foundation (FCT), project PTDC/DES/101224/2008 under Grant (FCOMP-010124-FEDER-009577).

\section{References}

Baba, R., Nagashima, M., Goto, M., Nagano, Y., Yokota, M., Tauchi, N., et al (1996). Oxygen uptake efficiency slope: A new index of cardiorespiratory functional reserve derived from the relation between oxygen uptake and minute ventilation during incremental exercise. Journal of the American College of Cardiology, 28, 1567-1572.

Baldari, C., Fernandes, R. J., Meucci, M., Ribeiro, J., Vilas-Boas, J. P., \& Guidetti, L. (2013). Is the new AquaTrainer ${ }^{\circledR}$ snorkel valid for VO ${ }_{2}$ assessment in swimming? International Journal of Sports Medicine, 34, 344-366.

Baron, B., Dekerle, J., Depretz, S., Lefevre, T., \& Pelayo, P. (2005). Self selected speed and maximal lactate steady state speed in swimming. Journal of Sports Medicine and Physical Fitness, 45, 1-6.

Baron, B., Dekerle, J., Robin, S., Neviere, R., Dupont, L., Matran, R., ... Pelayo, P. (2003). Maximal lactate steady state does not correspond to a complete physiological steady state. International Journal of Sports Medicine, 24, 582-587.

Baron, B., Noakes, T. D., Dekerle, J., Moullan, F., Robin, S., Matran, R., et al (2008). Why does exercise terminate at the maximal lactate steady state intensity? British Journal of Sports Medicine, 42, 828-833.

Beneke, R. (2003). Maximal lactate steady state concentration (MLSS): Experimental and modelling approaches. European Journal of Applied Physiology, 88, 361-369.

Beneke, R., \& von Duvillard, S. P. (1996). Determination of maximal lactate steady state response in selected sports events. Medicine and Science in Sports and Exercise, 28, 241-246.

Chatard, J. C., Lavoie, J. M., \& Lacour, J. R. (1991). Energy cost of front-crawl swimming in women. European Journal of Applied Physiology and Occupational Physiology, 63, 12-16.

Costill, D. L., Kovaleski, J., Porter, D., Kirwan, J., Fielding, R., \& King, D. (1985). Energy expenditure during front crawl swimming: Predicting success in middle-distance events. International Journal of Sports Medicine, 6, 266-270.

Craig, A. B., Jr., \& Pendergast, D. R. (1979). Relationships of stroke rate, distance per stroke, and velocity in competitive swimming. Medicine and Science in Sports, 11, 278-283.

Crewther, B., Cronin, J., \& Keogh, J. (2006). Possible stimuli for strength and power adaptation: Acute metabolic responses. Sports Medicine, 36, 65-78.

Dekerle, J., Nesi, X., Lefevre, T., Depretz, S., Sidney, M., Marchand, F. H., et al (2005). Stroking parameters in front crawl swimming and maximal lactate steady state speed. International Journal of Sports Medicine, 26, 53-58.

Dekerle, J., Pelayo, P., Clipet, B., Depretz, S., Lefevre, T., \& Sidney, M. (2005). Critical swimming speed does not represent the speed at maximal lactate steady state. International Journal of Sports Medicine, 26, 524-530.

Deschenes, M. R., \& Kraemer, W. J. (2002). Performance and physiologic adaptations to resistance training. American Journal of Physical Medicine and Rehabilitation, 81, S3-S16.

di Prampero, P. E. (1986). The energy cost of human locomotion on land and in water. International Journal of Sports Medicine, 7, 55-72.

di Prampero, P. E., Pendergast, D., \& Zamparo, P. (2011). Swimming economy (Energy Cost) and efficiency. In L. Seifert, D. Chollet, \& I. Mujika (Eds.), World book of swimming: From science to performance (pp. 297-312). New York: Nova.

Faude, O., Kindermann, W., \& Meyer, T. (2009). Lactate threshold concepts: How valid are they? Sports Medicine, 39, 469-490.

Fernandes, R. J., Billat, V. L., Cruz, A. C., Colaco, P. J., Cardoso, C. S., \& Vilas-Boas, J. P. (2006). Does net energy cost of swimming affect time to exhaustion at the individual's maximal oxygen consumption velocity? Journal of Sports Medicine and Physical Fitness, 46, 373-380.

Fernandes, R. J., de Jesus, K., Baldari, C., Sousa, A. C., Vilas-Boas, J. P., \& Guidetti, L. (2012). Different VO $_{2 m a x}$ time-averaging intervals in swimming. International Journal of Sports Medicine, 33, 1010-1015.

Fernandes, R. J., Sousa, M., Machado, L., \& Vilas-Boas, J. P. (2011). Step length and individual anaerobic threshold assessment in swimming. International Journal of Sports Medicine, 32, 940-946.

Figueira, T. R., Caputo, F., Pelarigo, J. G., \& Denadai, B. S. (2008). Influence of exercise mode and maximal lactate-steady-state concentration on the validity of OBLA to predict maximal lactate-steady-state in active individuals. Journal of Science and Medicine in Sport, 11, $280-286$.

Figueiredo, P., Nazário, R., Sousa, M., Pelarigo, J. G., Vilas-Boas, J. P., \& Fernandes, R. (2014). Kinematical analysis along maximal lactate steady state swimming intensity. Journal of Sports Science \& Medicine, 13, 610-615.

Fletcher, J. R., Esau, S. P., \& Macintosh, B. R. (2009). Economy of running: Beyond the measurement of oxygen uptake. Journal of Applied Physiology, 107, $1918-1922$. 
Fritzsche, R. G., Switzer, T. W., Hodgkinson, B. J., \& Coyle, E. F. (1999). Stroke volume decline during prolonged exercise is influenced by the increase in heart rate. Journal of Applied Physiology, 86, 799-805.

Gladden, L. B. (2008). A lactatic perspective on metabolism. Medicine and Science in Sports and Exercise, 40, 477-485.

Greco, C. C., Pelarigo, J. G., Figueira, T. R., \& Denadai, B. S. (2007). Effects of gender on stroke rates, critical speed and velocity of a 30-min swim in young swimmers. Journal of Sports Science E' Medicine, 6, 441-447.

Harms, C. A., Wetter, T. J., St Croix, C. M., Pegelow, D. F., \& Dempsey, J. A. (2000). Effects of respiratory muscle work on exercise performance. Journal of Applied Physiology, 89, 131-138.

Heck, H., Mader, A., Hess, G., Mucke, S., Muller, R., \& Hollmann, W. (1985). Justification of the 4-mmol/1 lactate threshold. International Journal of Sports Medicine, 6, 117-130

Holfelder, B., Brown, N., \& Bubeck, D. (2013). The influence of sex, stroke and distance on the lactate characteristics in high performance swimming. PLoS ONE, 8. 0077185.

Hollmann, W. (2001). 42 years ago-development of the concepts of ventilatory and lactate threshold. Sports Medicine, 31, 315-320.

Hopkins, S. R., \& Harms, C. A. (2004). Gender and pulmonary gas exchange during exercise. Exercise and Sport Sciences Reviews, 32, 50-56.

Machado, L., Almeida, M., Morais, P., Fernandes, R., \& Vilas-Boas, J. P. (2006). Assessing the individual anaerobic threshold: The mathematical model. In Xth international symposium of biomechanics and medicine in swimming (pp. 142-144). Portugal: Porto.

Pelarigo, J. G., Denadai, B. S., \& Greco, C. C. (2011). Stroke phases responses around maximal lactate steady state in front crawl. Journal of Science and Medicine in Sport, 14, 168.e1-168.e5.

Pelarigo, J. G., Denadai, B. S., Ribeiro, J., Fernandes, R. J., Greco, C. C., \& Vilas-Boas, J. P. (2014). Biophysics of the elite endurance swimmer: A case study during aerobic capacity evaluation using different methods. In B. Mason (Ed.), XIIth international symposium on biomechanics and medicine in swimming (pp. 318-325). Canberra, Australia: Australian Institute of Sport.

Rodriguez, F. A., \& Mader, A. (2011). Energy systems in swimming. In L. Seifert, D. Chollet, \& I. Mujika (Eds.), World book of swimming: From science to performance (pp. 225-240). New York: Nova.

Sheel, A. W., Richards, J. C., Foster, G. E., \& Guenette, J. A. (2004). Sex differences in respiratory exercise physiology. Sports Medicine, 34, 567-579.

Sousa, A. C., Vilas-Boas, J. P., \& Fernandes, R. J. (2014). VO 2 kinetics and metabolic contributions whilst swimming at 95, 100, and 105\% of the velocity at $\mathrm{VO}_{2 \max }$. BioMed Research International, 1, 1-9.

Tanaka, H., \& Swensen, T. (1998). Impact of resistance training on endurance performance. A new form of cross-training? Sports Medicine, 25, 191-200.

Tarnopolsky, M. A., Atkinson, S. A., Phillips, S. M., \& MacDougall, J. D. (1995). Carbohydrate loading and metabolism during exercise in men and women. Journal of Applied Physiology, 78, 1360-1368.

Toussaint, H. M., \& Hollander, A. P. (1994). Energetics of competitive swimming. Implications for training programmes. Sports Medicine, 18, 384-405. 